\title{
REPRESENTAÇÕES SOCIAIS DOS GESTORES E DOS TÉCNICOS DAS UNIDADES ACADÊMICAS DA UNIVERSIDADE FEDERAL DO CEARÁ (UFC) ACERCA DA AUTOAVALIAÇÃO INSTITUCIONAL
}

\author{
Wagner Bandeira Andriola* \\ Laura Alves de SouzA**
}

Recebido em: 04 de abril 2010

Aprovado em: 29 de abril de 2010

\begin{abstract}
*Psicólogo; Especialista em Psicometria (Universidade de Brasília - UnB); Mestre em Psicologia Social e do Trabalho (UnB); Doutor em Filosofia e Ciências da Educação (Universidad Complutense de Madrid); Professor Adjunto do Departamento de Fundamentos da Educação, Faculdade de Educação, Universidade Federal do Ceará (UFC); Coordenador de Avaliação Institucional (UFC); Coordenador da Comissão Própria de Avaliação (CPA/UFC); Bolsista de Produtividade em Pesquisa do CNPq. E-mail: w_andriola@ufc.br. Fone: $(++55-85)$ 3366-7414.

** Mestra em Políticas Públicas e Gestão da Educação Superior pelo programa de Mestrado Profissional em Políticas Públicas e Gestão da Educação Superior (POLEDUC) da Universidade Federal do Ceará (UFC). E-mail: laura@ufc.br.
\end{abstract}

Resumo: O objetivo desta pesquisa foi analisar a cultura avaliativa na Universidade Federal do Ceará (UFC), tendo como base as representações sociais dos gestores e dos técnico-administrativos das nove unidades acadêmicas dos campi de Fortaleza, que participaram do ciclo de Autoavaliação Institucional 2005/2006. Utilizamos como sujeitos da pesquisa os nove gestores que integram as referidas unidades acadêmicas e uma amostra de trinta e seis técnico-administrativos, quatro em cada unidade. Pela especificidade deste estudo, de natureza exploratória e descritiva, utilizamos o método indutivo, o que nos permitiu uma análise do particular para o geral, ou seja, a realização de inferências sobre as representações específicas de cada sujeito para a realidade da UFC. Como instrumento mais adequado à pesquisa de campo, utilizamos o questionário previamente estruturado. Indagamos sobre o SINAES e a política de avaliação, bem como a participação da comunidade interna no processo de Auto-Avaliação Institucional da UFC. Ao analisar as representações de cada segmento, concluímos que elas têm um caráter específico, não pelo fato de serem subjetivas, mas pela própria dinâmica social das condições nas quais se produzem e reproduzem. As representações dos gestores e técnico-administrativos apresentam especificidades em relação à inserção social e aos interesses inerentes de cada segmento.

Palavras-chave: Ensino Superior. Avaliação Institucional. SINAES. Representação Social. Cultura avaliativa.

\section{SOCIAL REPRESENTATIONS OF ADMINISTRATORS AND TECHNICIANS OF THE ACADEMIC UNITS OF FEDERAL UNIVERSITY OF CEARÁ (UFC) CONCERNING INSTITUTIONAL SELF-EVALUATION}

\footnotetext{
Abstract: The purpose of this study was to assess the evaluative culture at the Federal University of Ceará (UFC), based on the social representations of administrators as well as technical and administrative faculty of the academic units on the campus of Fortaleza which participated in the cycle of Institutional Evaluation 2005/2006. We used as subjects for this research the nine administrators who integrate these academic units and a sample of thirty-six technical and administrative staff, four in each unit. Due to the specificity of this exploratory and descriptive study, we used the inductive method, which allowed us to analyze from the individual to the general, that is, to infer about the specific representations of each subject to the reality of the UFC. As the most
} 
appropriate tool for field research, we used the previously structured questionnaire. We asked about SINAES and the evaluation policy, as well as internal community participation in the process of Institutional self-evaluation of UFC. In considering the representations of each segment, we found that they have a specific character, not because they are subjective, but by the social dynamics of the conditions in which they are produced and reproduced. Representations of the administrators as well as of the technical and administrative staff have specificities concerning social inclusion and interests which are inherent to each segment.

Key words: Educational Evaluation. Higher Education. SINAES. Social Representation. Evaluative culture.

\section{ALGUMAS CONSIDERAÇÕES ACERCA DA AVALIAÇÃO INSTITUCIONAL NO BRASIL}

Nos últimos anos, as reformas na Educação Superior tornaram-se acentuadas, principalmente a partir da década de 1980, diversificando-se os provedores, os tipos de instituições, os perfis dos docentes, disponibilizando-se novas ofertas educativas, ampliando-se as matrículas e apresentando-se um aumento crescente das demandas e da competitividade. Com o advento do mercado educacional globalizado, os países industrializados e os latino-americanos empreenderam importantes reformas nos seus sistemas de educação superior. A esses fatores, soma-se a crescente mercantilização da educação superior, com o surgimento de muitos centros universitários e faculdades particulares. (BRASIL, 2007; DIAS SOBRINHO; RISTOFF, 2003)

Atualmente, das 2.281 Instituições de Ensino Superior (divididas por categoria administrativa em Universidades, Centros Universitários, Faculdades Integradas, Faculdades, Escolas e Institutos, Centros de Educação Tecnológica - CET's e Faculdades de Tecnologia - FaT's), apenas 249 são públicas e 2.032 são privadas, ou seja, aproximadamente $89 \%$ são compostas por instituições privadas e somente $11 \%$ são públicas. (BRASIL, 2009)

Nessa perspectiva, ganha centralidade o processo de avaliação e de regulação da educação superior, sustentada por diversos argumentos, como a necessidade de o Estado assegurar a qualidade educacional, a distribuição e o uso adequado dos recursos públicos, a expansão segundo critérios estabelecidos por políticas institucionais do sistema, até mesmo a necessidade de dar fé pública à prestação de contas dessas instituições e de produzir informações úteis para a tomada de decisões. (DIAS SOBRINHO; RISTOFF, 2003)

O Programa de Avaliação Institucional das Universidades Brasileiras (PAIUB), que teve início em 1993 e o Exame Nacional dos Cursos (ENC), criado em 1995, revelam não somente o estado da avaliação em cada momento, mas também as concepções de avaliação: uma comprometida com a transfor- 
mação acadêmica, em uma perspectiva formativa e emancipatória (PAIUB); outra vinculada ao controle de resultados e ao valor de mercado, com uma visão regulatória (ENC), conforme Andriola (2008).

No Brasil, mesmo com a abertura política caracterizada pela redemocratização, há certo desgaste em relação à credibilidade dos processos avaliativos (BELLONI, 1999). A gênese deste descrédito pode estar relacionada com a reflexão de Fernandes (2001), que afirma que as experiências de avaliação institucional no país parecem ter sido, quase sempre, marcadas por certa verticalidade. Dias Sobrinho (2004) corrobora essa assertiva e cita características de algumas tentativas pontuais de avaliação:

- Está centrada exclusivamente nas atribuições de supervisão do MEC;

- Praticamente não considera instituições e cursos como sujeitos de avaliação;

- Não distingue adequadamente supervisão e avaliação, com nítida ênfase à primeira;

- Não constitui um sistema nacional de avaliação, porém, mais apropriadamente, uma justaposição de verificação de determinadas condições, unilateralmente defendidas pelo MEC.

Acrescentamos, ainda, a concepção política que está por trás do ato de avaliar. Neste sentido, a avaliação não é um procedimento meramente técnico ou burocrático. Independentemente do foco ideológico, a avaliação supõe valores e julgamentos a partir de referenciais que assumimos no contexto avaliativo. Sempre que emitimos um julgamento, está implícita uma dada visão de homem e de mundo. Os objetos e processos de avaliação não são casuais, nem resultado de uma dimensão técnica, eles revelam nosso projeto de avaliação e de educação. A simples seleção do que será avaliado já configura um ato político, supõe uma escolha por parte de quem vai proceder à avaliação. Avaliar o quê, para quê e para quem?

Nesse sentido, Demo (1999) enfatiza que seria ingênuo pensar a avaliação apenas como um processo técnico, dado ser ela também uma atividade política. Avaliar pode constituir um exercício autoritário do poder de julgar, ou, ao contrário, pode constituir um processo em que avaliador e avaliando buscam uma mudança qualitativa.

A constatação da presença ou ausência de algo não configura uma avaliação. É necessário ultrapassar a mensuração e classificação e chegar ao julgamento. Avaliação deve ter conseqüências: deve ser empregada por avaliadores e avaliados, com vistas à tomada de decisões, e não apenas configurar um ato 
formal e técnico, a ser engavetado. Nesta perspectiva, Zákia (2008) questiona que a avaliação apenas para fins burocráticos não causa transformação, não induz à ação e perde o seu sentido. Para ela, o processo avaliativo segue as etapas descritas abaixo, tendo como ponto de partida e de chegada o projeto de avaliação, ou seja, do diagnóstico à ação:

$$
\text { Descrição } \rightarrow \text { Análise } \rightarrow \text { Julgamento } \rightarrow \text { Decisão } \rightarrow \text { Ação }
$$

É necessário transcender o caráter burocrático da avaliação, romper com as resistências e ampliar o seu conceito apenas classificatório. Mesmo com a abertura política caracterizada a partir dos anos 1980, reforçamos que, no Brasil, há certo desgaste em relação à credibilidade dos processos avaliativos.

Nesse contexto, o Relatório Final de Auto-Avaliação Institucional da UFC (2006) constatou substancial desmotivação no tocante à participação dos atores internos. Como referido no Relatório, tal fato pode refletir certa despolitização, algo bastante sintomático na atual conjuntura interna da mencionada Instituição Federal de Educação Superior (IFES).

\section{SINAES: O ATUAL MOMENTO HISTÓRICO DA AVALIAÇÃO INSTITUCIONAL DA EDUCAÇÃO SUPERIOR BRASILEIRA}

A atual legislação da avaliação institucional no âmbito da educação superior brasileira é estabelecida pela Lei 10.861, de 14 de abril de 2004, que instituiu o Sistema Nacional de Avaliação da Educação Superior (SINAES). A proposta original do Sistema Nacional de Avaliação intitulada SINAES: bases para uma proposta de avaliação da Educação Superior foi apresentada pela Comissão Especial de Avaliação da Educação Superior (CEA), em agosto de 2003. Está implícita no subtítulo a ideia de que o texto não era uma proposta pronta, acabada, mas a base, o ponto de partida para a construção de um autêntico Sistema Nacional de Avaliação da Educação Superior. (BRASIL, 2007)

O SINAES é formado por três procedimentos avaliativos: a Avaliação das Instituições de Educação Superior (AVALIES), constituída da Auto-avaliação e da Avaliação Externa; a Avaliação dos Cursos de Graduação (ACG) e o Exame Nacional de Desempenho dos Estudantes (ENADE).

Uma concepção central de avaliação deve assegurar coerência conceitual, epistemológica e prática, por meio de princípios, critérios, pressupostos e premissas que fundamentam a operacionalização dos processos. Nesse sentido, o SINAES tem como princípios (BRASIL, 2007): 
REPRESENTACÕES SOCIAIS DOS GESTORES E DOS TÉCNICOS DAS UNIDADES ACADÊMICAS DA UNIVERSIDADE FEDERAL DO CEARÁ (UFC) ACERCA DA AUTOAVALIAÇÃO INSTITUCIONAL

- Responsabilidade social com a qualidade da educação superior;

- Reconhecimento à diversidade do sistema;

- Respeito à identidade, à missão e à história das IES;

- Globalidade institucional;

- Continuidade do processo avaliativo como instrumento de política educacional;

- Regulação, não com um fim em si mesma, mas articulada a uma avaliação formativa e construtiva.

Uma das críticas mais constantes às práticas avaliativas vigentes nos últimos anos é o uso de instrumentos isolados, que conduzem a uma visão parcial e fragmentada da realidade, não dando conta da riqueza e da complexidade da educação. Isso requer a utilização de múltiplos instrumentos, bem como a combinação de diversas metodologias. (BRASIL, 2007)

Tomando como referência atual o SINAES, percebemos que este é um sistema que combina regulação e avaliação da educação superior. Porém, em relação aos sistemas anteriormente vigentes, o SINAES traz uma mudança de paradigma, principalmente no que diz respeito ao conceito de avaliação e de educação superior. Não se trata de uma opção técnica, mas, sobretudo, filosófica e política. De acordo com Dias Sobrinho (2004), essa mudança de paradigma se evidencia nos seguintes aspectos:

- Mútua alimentação de avaliação e de regulação, em que a avaliação subsidia o processo regulatório;

- Coesão entre os distintos instrumentos articulados e ampliação de concepções e práticas anteriores (atores, objetos, procedimentos, instrumentos);

- Ampliação da concepção de educação superior, não se limitando ao ensino, mas à educação em suas dimensões técnicas, éticas, políticas e filosóficas;

- Ampliação da concepção de formação, tendo como referência princípios de cidadania e da ética;

- Ampliação dos sujeitos envolvidos, de forma que todos os atores componentes da comunidade universitária tenham prerrogativa de participação na auto-avaliação;

- Ampliação da função dos avaliadores que assumirão funções formativas e não se limitarão à prática de checagem para efeito de rankings;

- Contribuição para a profissionalização na área de avaliação, evitando as improvisações, deficiências conceituais e ausência de critérios; 
- Adaptação dos instrumentos vigentes (curso, cadastro, avaliação da PósGraduação) à nova concepção e aos objetivos da avaliação;

- Valorização de processos formativos e abordagens qualitativas; introdução de prática da meta-avaliação;

- Oferecimento à sociedade de informações baseadas em dados institucionais e ajuda para articular os distintos setores da Educação Superior do MEC (SESu, INEP, SEMTEC, CAPES, etc);

- Valorização da solidariedade e da cooperação entre as IES, com destaque para a responsabilidade social da Educação Superior.

\section{A AUTO-AVALIAÇÃO INSTITUCIONAL DA UNIVERSIDADE FEDERAL DO CEARÁ (UFC)}

O processo de avaliação institucional da UFC, ciclo 2005/2006, tem base na Lei Federal que instituiu o SINAES. Iniciou-se com a escolha e nomeação dos membros da Comissão Própria de Avaliação (CPA), através da portaria $\mathrm{N}^{\circ}$ 922, de 11 de junho de 2004, do Magnífico Reitor Prof. René Teixeira Barreira, homologada pelo Conselho Universitário (CONSUNI) em 22 de setembro de 2004, data a partir da qual se iniciaram, de fato, as atividades de auto-avaliação institucional da UFC. As valorações das atividades de auto-avaliação baseiamse em dados relativos ao período posterior à criação do SINAES e referem-se ao intervalo de 2004 a 2006.

Como instrumental destinado à coleta de dados úteis ao processo de avaliação institucional, de acordo com o Relatório Final de Auto-Avaliação Institucional da UFC (2006), utilizou-se questionários semi-abertos, abordando as várias dimensões institucionais. A aplicação dos questionários foi executada pelos membros das CPA's setoriais, que realizaram audiências com os diretores das unidades acadêmicas, chefes de departamento, coordenadores de cursos de graduação e de pós-graduação, coordenadores de projetos de extensão, diretores de bibliotecas, superintendente de recursos humanos, calouros e egressos dos cursos de graduação. As informações obtidas nas questões foram tratadas qualitativamente, por análise de conteúdo, conforme propõe Bardin (2004), a qual consiste em identificar as categorias de respostas mais relevantes.

Para a participação dos discentes e docentes de graduação e pós-graduação, e dos servidores técnico-administrativos, utilizaram-se formulários eletrônicos disponibilizados na web page da UFC, no período de março a junho de 2006. Além dos dados primários, descritos anteriormente, a CPA central lançou mão 
REPRESENTAÇÕES SOCIAIS DOS GESTORES E DOS TÉCNICOS DAS

UNIDADES ACADÊMICAS DA UNIVERSIDADE FEDERAL DO CEARÁ (UFC)

ACERCA DA AUTOAVALIAÇÃO INSTITUCIONAL

de dados secundários, tais como Revista Universidade Pública, UFC Fax, Jornal da UFC, Sistema on-line de Dados e Indicadores da Qualidade Institucional da UFC (CAIA/PRPL), Sistema do Censo de Educação Superior (SIEDSUP-MEC/ INEP) e Relatórios Anuais de Atividades e de Gestão da UFC.

A CONAES sugere um roteiro de Auto-Avaliação Institucional constituído de dez dimensões. Cada IES seleciona os itens que correspondem às suas atividades, além de propor seus próprios temas complementares. O Relatório de Auto-Avaliação Institucional da UFC abrangeu as dez dimensões e acrescentou outras três: a dimensão zero, contextualizando a UFC; a dimensão onze, sobre as atividades do complexo hospitalar; e a dimensão doze, na qual foi realizada uma meta-avaliação.

Visando ao aprimoramento de atividades administrativas e acadêmicas, após a análise de cada dimensão, o Relatório Final de Auto-Avaliação Institucional da UFC (2006), lançou as seguintes propostas para a operacionalização de ações futuras:

\section{- Missão e Plano de Desenvolvimento Institucional da UFC}

Ampla divulgação interna para que a comunidade conheça o PDI e o PPI; incentivo à participação da comunidade interna da UFC durante a elaboração dos referidos documentos.

- Política Institucional para o Ensino, a Pesquisa, a Pós-Graduação e a Extensão

Ações institucionais visando reduzir o número de interrupções de matrículas nos cursos de graduação; incrementar a interdisciplinaridade entre cursos de graduação, sobretudo no que tange à formação discente; aumentar o relacionamento entre graduação e pós-graduação.

\section{- Responsabilidade Social na UFC}

Aumento do número de bolsas destinadas aos discentes de graduação com menor poder aquisitivo; maior apoio financeiro às atividades artísticas $\mathrm{e}$ culturais desenvolvidas pelo ICA e prosseguimento das melhorias nas residências universitárias.

\section{- Comunicação Interna e Externa da UFC}

Iniciar melhorias significativas nos setores da comunicação interna e externa da UFC; garantir maior aporte de equipamentos, de recursos humanos especializados e apoio financeiro para o adequado funcionamento dos diversos mecanismos de comunicação. 


\section{- Políticas Internas de Gestão de Pessoal}

Implementar estudos internos a fim de detectar o grau de satisfação no trabalho dos servidores da UFC e a qualidade das relações interpessoais; análise dos quantitativos de recursos humanos e das demandas internas; ampla discussão interna sobre o uso que se faz dos dados resultantes das sistemáticas avaliativas de docentes e técnico-administrativos.

\section{- Gestão Administrativa e Organização da UFC}

Buscar ações internas para aperfeiçoar o controle de pessoal docente e técnico-administrativo; aprofundar as ações institucionais de combate ao desperdício; iniciar amplos estudos para o aperfeiçoamento da segurança interna; adequar os programas internos de incentivo à publicação de livros às demandas internas; incrementar os investimentos no ensino da graduação e da pós-graduação; aumentar e adequar o acervo bibliográfico às necessidades dos aprendizes; aperfeiçoar o modelo interno para a distribuição de vagas para novos docentes; garantir apoio financeiro para o desenvolvimento do sistema informatizado para a gestão de dados e informações administrativas e acadêmicas.

- Adequação da InfraEstrutra Física, dos Equipamentos e das Bibliotecas

Ampliar o número de profissionais especializados no âmbito das bibliotecas; garantir o funcionamento das bibliotecas até às 22 horas, para atender os discentes dos cursos noturnos; aumentar a quantidade de computadores nas bibliotecas; adequar o acesso às bibliotecas aos portadores de necessidades especiais de locomoção; adequação de iluminação, refrigeração, segurança e de equipamentos para combate a incêndio; expansão e manutenção do acervo bibliográfico existente; investimento para melhoria física das salas de aula, laboratórios e bibliotecas; planejamento e construção de áreas de convivência destinadas à interação entre os profissionais da UFC.

\section{- Avaliação e Planejamento Institucional}

Priorizar o planejamento institucional participativo, atrelado à sistemática de auto-avaliação; institucionalizar a atividade de auto-avaliação da UFC; apoiar a realização de seminários internos para disseminar dados resultantes da auto-avaliação institucional, do Censo da Educação Superior e do ENADE; incentivar grupos de estudo envolvendo diretores de Unidades Acadêmicas, chefes de departamento e coordenadores de cursos, com o objetivo de refletirem o planejamento e aprimoramento do respectivo setor; desencadear ações 
REPRESENTAÇÕES SOCIAIS DOS GESTORES E DOS TÉCNICOS DAS

UNIDADES ACADÊMICAS DA UNIVERSIDADE FEDERAL DO CEARÁ (UFC)

ACERCA DA AUTOAVALIAÇÃO INSTITUCIONAL

institucionais a fim de informar à comunidade interna acerca dos benefícios da auto-avaliação institucional e do planejamento participativo; garantir recursos no orçamento da UFC destinados à auto-avaliação institucional.

- Política Institucional de Atendimento aos Discentes e de Acompanhamento aos Egressos

Desenvolver um Sistema de Orientação e Informação (SOI) aos egressos do Ensino Médio, potenciais candidatos aos cursos de graduação oferecidos pela UFC; dinamizar a interação entre os cursos; apoiar o trabalho dos coordenadores de cursos pelo maior aporte de equipamentos e melhoria das instalações físicas; garantir as atualizações curriculares e dos Projetos Políticos Pedagógicos dos Cursos.

\section{- Sustentabilidade financeira}

Priorizar o uso do superávit orçamentário em ações visando à diminuição de transferências e evasões de discentes da graduação, através do incremento das bolsas de estudo; incrementar a ajuda de custo aos discentes que tenham trabalhos aceitos em congressos científicos ou similares; aprimorar a qualidade física das salas de aula, dos laboratórios, das bibliotecas, de construção de áreas de convivência; garantir apoio financeiro às publicações de livros e similares.

\section{- Complexo Hospitalar da UFC}

Melhor publicidade aos agentes internos e externos à UFC em relação aos produtos conseguidos por ações internas e externas do HUWC e da MEAC.

No âmbito interno, a auto-avaliação da UFC inferiu, através do Relatório Final (2006) suas dificuldades no processo avaliativo, entre as quais citamos os baixos níveis de participação, tanto da CPA quanto dos discentes, docentes e técnico-administrativos. Acreditamos que o principal fator que contribui para os baixos índices de participação seja a ausência de uma cultura de avaliação participativa na UFC, caracterizada por um contexto de despolitização, que vai além dos limites institucionais e atinge a esfera nacional.

\section{DEFINIÇÃO DAS CATEGORIAS CULTURA, REPRESENTAÇÃO SOCIAL E ANÁLISE DE CONTEÚDO}

Ao considerar a participação de todos os sujeitos envolvidos pelo cotidiano universitário e a adesão voluntária para as instituições, a proposta do SINAES se caracteriza como uma atividade democrática, que valoriza o engajamento de todos e estimula o desenvolvimento de uma cultura avaliativa. 
A cultura é socialmente construída. Ela se processa no desenrolar da própria realidade vivida. Nesse sentido Morgan (1996) salienta que a vida dentro de uma cultura flui muito suavemente; somente quando alguém quebra um padrão com uma ação desorganizadora ou questiona essa realidade, percebe-se a sutileza do cotidiano. Porém, a habilidade de se aplicar uma regra pede muito mais do que o conhecimento da regra em si, pois isso não garante que ela seja cumprida. Somente quando essa ideia passa a fazer parte da cultura é que ela que adquire legitimidade e se processa de forma não impositiva.

O conceito de cultura adotado neste trabalho está fundamentado em Morgan (1996, p. 143), que a definiu como:

[...] Uma forma muito desenvolvida de prática social, influenciada por muitas interações complexas entre pessoas, situações, ações, circunstâncias. Embora possa ser vista como um padrão visível refletindo costumes, crenças, histórias, rituais, normas, este padrão é apenas uma abstração imposta pela cultura, a partir do exterior, que ajuda o observador a dar sentido ao que está acontecendo na cultura, mas, não é sinônimo da experiência da cultura em si mesma.

A cultura vista apenas como um conjunto de variáveis distintas como crenças, normas, rituais, é uma visão mecanicista e leva a inferir que esta pode ser manipulada de maneira instrumental. A difusão da cultura, segundo Morgan, ocorre de maneira holográfica, ou seja, não leva ao controle direto por nenhum grupo de indivíduos em particular.

A definição de cultura de acordo com Morgan não encerra a idéia de que esta possa ser manipulada de maneira instrumental. Esse tipo de visão mecanicista é característico de perspectivas que defendem a administração da cultura. Os gestores podem até influenciar a evolução da cultura através de suas representações simbólicas e tentar promover valores desejados. Compreender a cultura de uma instituição pode abrir os olhos para algumas descobertas, mas isso não oferece uma receita na resolução dos problemas. Pode-se até usar algumas variáveis culturais para obter determinados resultados, mas surge como algo inviável administrar a cultura em si.

Nesse sentido, quando se fala na necessidade de se instituir uma cultura de avaliação nas IES, Suanno (2002) considera a cultura avaliativa um princípio metodológico da avaliação institucional, e não um instrumento. Portanto, pode-se estimular o processo através do direcionamento de algumas variáveis culturais, o que Andriola (2005) caracteriza como sensibilização da comunidade interna acerca do processo de avaliação. 
O processo de Auto-Avaliação Institucional, de acordo com Suanno (2002), por ter caráter pedagógico há de promover e incentivar uma cultura avaliativa que seja construtiva, participativa, permanente, comprometida com os objetivos do projeto avaliativo. No entanto, devemos lembrar que a aculturação de novos hábitos não se dá de forma automática nem imediata: a construção de uma cultura de avaliação é um processo que demanda tempo, continuidade, informação e reflexão capaz de provocar consciência institucional e novas atitudes mentais.

Morgan sugere, que em certo sentido, a natureza de uma cultura seja encontrada nas suas normas sociais e costumes, porém na maioria das circunstâncias o processo de fazer sentido ocorrerá somente se o comportamento for desafiado. Para ela, isso parece ser mais devido à cultura do que ao surgimento de regras. $\mathrm{E}$, mais que isso, embora frequentemente nos vejamos como vivendo em uma realidade com características objetivas, as solicitações da vida pedem muito mais de nós do que isso. Elas requerem que assumamos um papel ativo em trazer as nossas realidades à tona, por meio de vários esquemas representativos, mesmo que essas realidades tenham o hábito de se imporem sobre nós "da forma que as coisas são". Nesse contexto, Morgan infere que cultura é representação e não obediência a regras.

Tomando como base a relação estabelecida por Morgan entre cultura e representação, procuramos entender o que é representação social e como se processa esse vínculo entre cultura e representação.

Ao reconhecer que atingimos ou representamos a realidade do mundo diário, de acordo com Morgan, temos uma forma poderosa de pensar sobre cultura. Quando compreendida dessa forma, a cultura não pode mais ser vista como uma simples variável que as sociedades ou as organizações possuem, mas deve ser compreendida como um fenômeno ativo, vivo, mediante o qual as pessoas criam e recriam os mundos dentro dos quais vivem.

A necessidade de estarmos informados sobre o mundo à nossa volta, de acordo com Jodelet (2001), nos leva a criar representações, para compreendêlo, administrá-lo ou enfrentá-lo. As representações são fenômenos complexos e estão sempre em ação na vida social nos discursos, trazidas nas palavras e veiculadas em mensagens e imagens midiáticas, cristalizadas em condutas e em organizações. Sua riqueza como fenômeno, conforme a autora se manifesta pelos diversos elementos informativos, cognitivos, ideológicos, normativos, crenças, valores, atitudes, opiniões e imagens. É a essa totalidade significante, que se encontra no centro da investigação científica, que atribui como tarefa descrevê-la, analisá-la, explicá-la, em suas dimensões e formas, processos e funcionamento. 
A definição da categoria representação social nesse trabalho está de acordo com Jodelet (p. 8), que a concebeu como uma forma de conhecimento, socialmente elaborada e partilhada, com um objetivo prático, e que contribui para a construção de uma realidade comum a um conjunto social. A autora destaca que as representações sociais, na qualidade de fenômenos cognitivos, envolvem a pertença social dos indivíduos com as implicações afetivas e normativas, com as interiorizações de experiências, práticas, modelos de condutas e pensamentos socialmente inculcados ou transmitidos pela comunicação social, que com elas têm relação. O lugar, a posição social ou as funções que os indivíduos ocupam determinam os conteúdos representacionais e sua organização.

Nesse sentido, Bourdieu (2007, p. 119) faz um confronto entre as representações sociais e as relações de poder, tendo como fio condutor as divisões sociais:

O efeito simbólico exercido pelo discurso científico na produção da crença da unidade (tanto no seio do próprio grupo como nos outros grupos) tende a gerar a unidade real. Nada há de menos inocente do que a questão, que divide o mundo douto do saber se se devem incluir critérios pertinentes não só as propriedades ditas objetivas (como a ascendência, o território, a língua, a religião, a atividade econômica), mas também as propriedades ditas subjetivas (como o sentimento de pertença), quer dizer, as representações que os que os agentes sociais têm das divisões da realidade é que contribuem para a realidade das divisões.

Spink (1993) corrobora a definição de Jodelet (2001) e define representação como um conhecimento prático orientado para a comunicação e para a compreensão do contexto social, material e ideativo em que vivemos. Elas se manifestam como elementos cognitivos através de imagens, conceitos, categorias, teorias, mas não se reduzem jamais aos componentes cognitivos. Sendo socialmente elaboradas e compartilhadas, contribuem para elaboração de uma realidade comum, que possibilita a comunicação. Desse modo, as representações são fenômenos sociais que, mesmo acessados desde o seu conteúdo cognitivo, têm que ser entendidas a partir do seu contexto de produção, ou seja, iniciando pelas funções simbólicas e ideológicas a que servem e das formas de comunicação onde circulam.

Apesar dos múltiplos campos de estudo das representações sociais, com base em estudos de Jodelet (2001), Spink (1993) assinala a importância da definição precisa do aspecto a ser abordado no estudo. A representação social constitui um processo de mediação que compõe a relação sujeito-objeto da seguinte forma: o sujeito constrói o conhecimento pela interpretação que ob- 
tém do objeto; no cotidiano, a prática social expressa a representação através dos elementos cognitivos (imagens, conceitos) que o sujeito tem do objeto. Necessário se faz, nessa construção da realidade, compreender as condições de produção e reprodução da mensagem, com as suas variáveis psicológicas, sociológicas, ideológicas, culturais, a fim de identificar o que se interpõe nas entrelinhas dos discursos.

Caracterizando nosso tema de estudo, ou, como salienta Spink (1993), delimitando o campo das representações em um contexto, temos como objeto a avaliação institucional e como sujeito os gestores e técnicos que compõem a realidade interna da UFC. É na manifestação das representações sociais na realidade cotidiana que percebemos a concepção e as imagens que caracterizam a cultura avaliativa na UFC.

\subsection{Análise de conteúdo: definição, campo de atuação e inferência}

Um processo de comunicação eficiente exige ir além dos significados imediatos. Por isso, a análise de conteúdo propõe afastar-se do perigo da compreensão espontânea e lutar contra a evidência do saber subjetivo, o que demanda uma atitude de vigilância crítica, principalmente quando o pesquisador tem a impressão de familiaridade com seu objeto de análise.

É dizer não à limitação simples do real, sempre sedutora, forjar conceitos operatórios, aceitar o caráter provisório das hipóteses, definir planos experimentais ou de investigação (para despistar as primeiras impressões, como diria P. H. Lazarsfeld), sem que se caia na armadilha de sucumbir à magia dos instrumentos metodológicos, esquecendo-se a razão de seu uso. (BARDIN, 2004, p. 24)

A sutileza do método, conforme propõe Bardin (2004), corresponde aos seguintes objetivos:

- a superação da incerteza - o que eu julgo ver na mensagem estará lá efetivamente contido? Será minha leitura válida e generalizável?

- o enriquecimento da leitura - se um olhar imediato, espontâneo, é já fecundo, não poderá uma leitura atenta proporcionar a descoberta de conteúdos que se confirmam (ou infirmam) ou a significação de mecanismos cuja compreensão não detínhamos a priori?

A partir disso, a autora infere que o desenvolvimento histórico e o aperfeiçoamento da análise de conteúdo oscilam entre duas tendências, o desejo 
de rigor e a necessidade de aprofundar-se à superfície das aparências. Metodologicamente, confrontam-se ou completam-se duas orientações, a verificação prudente ou a interpretação brilhante.

Mas, o que é análise de conteúdo? Qual o seu campo de atuação? Quais as suas fronteiras? Para que serve? Enfim, o que, por que, como, onde, estas são as indagações que procuraremos esclarecer apoiados no pensamento de Bardin.

Para a autora, a análise de conteúdo é um conjunto de técnicas de tratamento das comunicações. Porém, como o campo das comunicações é muito vasto, parece difícil definir análise de conteúdo pelo seu território, pois, a princípio, tudo o que é comunicação (e até significação) parece suscetível de análise. De acordo com Bardin o que realmente tipifica a análise de conteúdo é a inferência de conhecimentos relativos às condições de produção (ou, eventualmente, de recepção), inferência esta que recorre a indicadores (quantitativos ou não). $\mathrm{O}$ analista tira partido do tratamento das mensagens que manipula para inferir (deduzir de maneira lógica) conhecimentos sobre o emissor da mensagem ou sobre o seu meio. Então, se a descrição (enumeração de características do texto, resumidas após o tratamento) é a primeira fase e a interpretação (significação concedida a estas características) é a última, a inferência é o procedimento intermediário e mediador do processo.

Mesmo admitindo ser a inferência algo que tipifica a análise de conteúdo, Bardin questiona que o processo dedutivo ou inferencial a partir de índices ou indicadores não é raro na prática científica, e é utilizado por profissionais das mais diversas áreas, delegando ao analista uma dupla tarefa: compreender o sentido da comunicação, mas também, e, principalmente, desviar a perspectiva para uma outra significação. A leitura não é unicamente "à letra", mas antes o realce de um sentido que se encontra em segundo plano.

Por fim, Bardin (2004, p. 37) define o termo análise de conteúdo (campo, funcionamento, objetivos) com o seguinte enunciado:

[...] um conjunto de técnicas de análise das comunicações visando obter, por procedimentos sistemáticos e objetivos de descrição do conteúdo das mensagens, indicadores (quantitativos ou não) que permitam a inferência de conhecimentos relativos às condições de produção/recepção (variáveis inferidas) destas mensagens.

$\mathrm{Na}$ análise de conteúdo, não existe o pronto-a-vestir, ou seja, não existe algo pronto e acabado ou um modelo para seguir. Existem somente algumas regras de base, por vezes dificilmente intransponíveis, daí Bardin apontar que a análise de conteúdo deve ser reinventada a cada momento. $\mathrm{O}$ analista possui um conjunto de técnicas analíticas ou complementares, adaptadas conforme a 
natureza do material ou à questão que procura resolver, de modo a enriquecer os resultados, ou aumentar sua veracidade, aspirando a uma interpretação final fundamentada.

\section{DELINEAMENTO DA PESQUISA}

\subsection{Objetivos}

A pesquisa apresenta os seguintes objetivos:

\section{- Objetivo geral}

- Analisar a cultura avaliativa na Universidade Federal do Ceará, tendo como base as representações sociais dos diversos segmentos das unidades acadêmicas dos campi de Fortaleza.

\section{- Objetivos específicos}

- Identificar as representações sociais dos gestores e técnicos sobre o processo de Auto-Avaliação Institucional na UFC.

- Analisar as representações acerca da auto-avaliação institucional a partir da dinâmica social (lugar, posição, funções) em que elas se produzem e reproduzem,

\subsection{Método}

Pela especificidade deste estudo, que se caracteriza como uma pesquisa quanti-qualitativa, de natureza exploratória e descritiva, utilizamos o método indutivo, com o apoio da técnica de análise de conteúdo, apenas nas questões abertas (opiniões, justificativas, outros), o que nos permitiu fazer inferências sobre o discurso dos sujeitos participantes e as representações sociais que eles transmitem, associando-os à realidade da UFC.

\subsection{Sujeitos do estudo}

- Gestores: o universo dos atuais diretores de centro e faculdades que participaram do ciclo de Avaliação Institucional 2005/2006. ${ }^{1}$

-Técnico-administrativos: uma amostra de quatro servidores técnicoadministrativos de cada Diretoria de Centro ou Faculdade que participou do ciclo de Avaliação Institucional 2005-2006, totalizando 36 técnicoadministrativos.

1 Os Diretores do Instituto de Cultura e Arte (ICA) e do Instituto de Ciências do Mar (LABOMAR) não farão parte da amostra porque não participaram do Ciclo de Avaliação Institucional 2005-2006, uma vez que, na época, essas unidades, ainda não haviam sido criadas como unidades acadêmicas. 


\subsection{Instrumentos}

-Questionário para os gestores: utilizamos um questionário previamente estruturado com seis questões (uma aberta e cinco fechadas), enfatizando diferentes aspectos associados ao SINAES, à cultura avaliativa e à participação dos atores internos no processo de Auto-Avaliação Institucional 2005-2006.

-Questionários para os técnico-administrativos: utilizamos um questionário previamente estruturado com cinco questões fechadas, enfatizando diferentes aspectos associados ao SINAES, cultura avaliativa e participação dos atores internos no processo de AutoAvaliação Institucional 2005-2006.

\subsection{Procedimentos}

Os questionários foram aplicados no período de março a maio de 2009, após agendarmos visitas por telefone, enviarmos e-mail, de utilizarmos os contatos pessoais com servidores que mediaram a obtenção de informações. Foi um processo demorado devido aos muitos compromissos e atividades que esses profissionais assumem. Em centros e faculdades em que o diretor não teve disponibilidade para responder o formulário, realizamos a pesquisa com o vice-diretor (Centro de Ciências) e com o coordenador do curso (Faculdade de Direito), e técnico-administrativos da Coordenação do Curso (Medicina).

Em um primeiro momento, os questionários foram analisados quantitativamente, separados por categoria, tabulados, e foi calculada a freqüência relativa de cada variável. Em seguida, foram analisados qualitativamente, através do emprego da técnica da análise de conteúdo, conforme propõe Bardin (2004), que consiste em identificar as categorias de respostas mais relevantes, presentes nas informações obtidas e inferir através do conteúdo os significados, as representações que estão implícita ou explicitamente em cada resposta. Por fim, foram confrontadas as categorias elaboradas teoricamente com as representações dos respondentes, proporcionando articulações entre o referencial teórico e as questões levantadas pela pesquisa.

\section{REPRESENTAÇÕES SOBRE O SINAES E O PROCESSO DE AUTO-AVALIAÇÃO INSTITUCIONAL DA UFC}

\subsection{Análise dos questionários dos gestores}

Perguntamos aos gestores se eles conhecem a proposta de avaliação institucional do Sistema Nacional de Avaliação da Educação Superior - SINAES. A análise das respostas nos permitiu a construção do seguinte gráfico. 


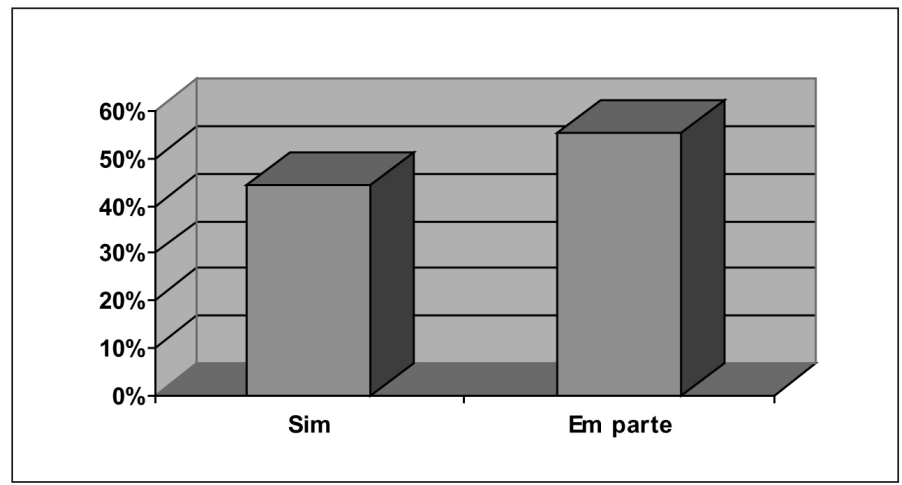

Gráfico 1 - Conhecimento dos gestores sobre o SINAES

Maior parte dos gestores (56\%) relatou conhecer, em parte, a sistemática de avaliação do SINAES, sendo que $44 \%$ responderam que conheciam o processo avaliativo. De modo geral, pode-se dizer que $100 \%$ dos gestores que participaram da pesquisa conhecem, no todo ou em parte, a sistemática de avaliação do SINAES.

A seguir, indagamos como concebiam a avaliação institucional. Oferecemos cinco fatores explicativos e deixamos um item em aberto para que pudessem acrescentar outros. Vejamos o resultado por ordem de escolha (os gestores podiam escolher mais de um fator).

a) Para $44 \%$ dos gestores, se trata de uma ferramenta capaz de ampliar o conhecimento das instituições e de sedimentar compromissos.

b) Para outros $44 \%$ é uma ferramenta que pode influenciar na melhoria da gestão universitária.

c) Segundo 33\% é um recurso que constitui critério de apoio financeiro ou de outra natureza.

Enfim, os gestores concebem a avaliação institucional como uma ferramenta que busca o conhecimento das instituições, objetivando melhoria da gestão universitária, e buscando apoio para sedimentar os compromissos financeiros ou outra natureza.

Comentamos com os gestores os índices de participação dos três segmentos que compõem a UFC no processo de Auto-Avaliação Institucional 2005/2006 por meio dos formulários disponibilizados no site (docentes: 24\%; discentes: $15 \%$; técnico-administrativos: $9 \%$ ). Perguntamos quais os fatores que 
poderiam estar associados aos baixos índices de participação no processo de Auto-Avaliação Institucional da UFC. Sugerimos quatro fatores explicativos e deixamos um em aberto para outras contribuições (os gestores podiam escolher mais de um fator). Obtivemos o seguinte resultado.

a) Para a expressiva maioria (89\%) dos gestores, esses baixos índices se devem à ausência de cultura de avaliação com visão construtiva e participativa.

b) Para $22 \%$ dos gestores, por conta da falta de informação sobre os objetivos e a importância da auto-avaliação.

c) Outros $22 \%$ de gestores asseveraram que ser devido ao processo de despolitização da comunidade interna das IFES que, cética aos projetos para a área educacional, reage com certo descrédito ao SINAES.

Analisando os dados, vemos que, para a expressiva maioria dos gestores, o problema da falta de participação no processo de auto-avaliação institucional reside na ausência de uma cultura de avaliação com visão construtiva e participativa. A falta de informação e a despolitização são fatores secundários, provavelmente decorrentes da inexistência de uma cultura avaliativa.

Refletimos sobre o fato de, no Brasil, mesmo com a abertura política caracterizada pela redemocratização, haver certo desgaste em relação à credibilidade dos processos avaliativos. Perguntamos acerca dos fatores associados a esse desgaste de credibilidade. Oferecemos quatro opções e deixamos um item em aberto para outras sugestões (os gestores podiam escolher mais de um fator). Vejamos o resultado.

a) Para a maioria dos gestores (67\%), as experiências de avaliação institucional no país, quase sempre, parecem ter sido marcadas por certa verticalidade.

b) Para $22 \%$, as propostas de avaliação estão centradas exclusivamente nas atribuições de supervisão do MEC.

c) Outros $22 \%$ asseveraram que são programas gerencialistas, que praticamente não consideram as instituições e os cursos como sujeitos.

Dois gestores acrescentaram comentários sobre o desgaste dos processos avaliativos no Brasil: a) não é levado em conta o fato de que os que vivenciam o processo têm que elaborar os instrumentos de avaliação; b) principalmente no governo $\mathrm{FHC}$, estas políticas estiveram vinculadas às políticas neoliberais 
de restrição fiscal e orçamentária e à privatização. Entretanto, de modo geral, a maioria dos gestores considerou que esse desgaste está relacionado com o fato de que as experiências de avaliação institucional no país, quase sempre, foram marcadas por certa verticalidade, ou seja, constituem projetos prontos e acabados, nos quais as instituições apenas gerenciam as determinações do MEC.

Posteriormente, lançamos um enunciado de Chauí (2000), no qual se afirma que a gênese da cultura brasileira tem raízes fincadas no autoritarismo e no poder centralizador. Determinadas conjunturas históricas, que em si foram superadas, se atualizam e ganham novas roupagens nos diversos aspectos da nossa vida social, econômica e política. Com base em Chauí (2000), indagamos se conceitos negativos e experiências antidemocráticas de avaliação poderiam influenciar nos níveis de participação social, com o resultado seguinte.

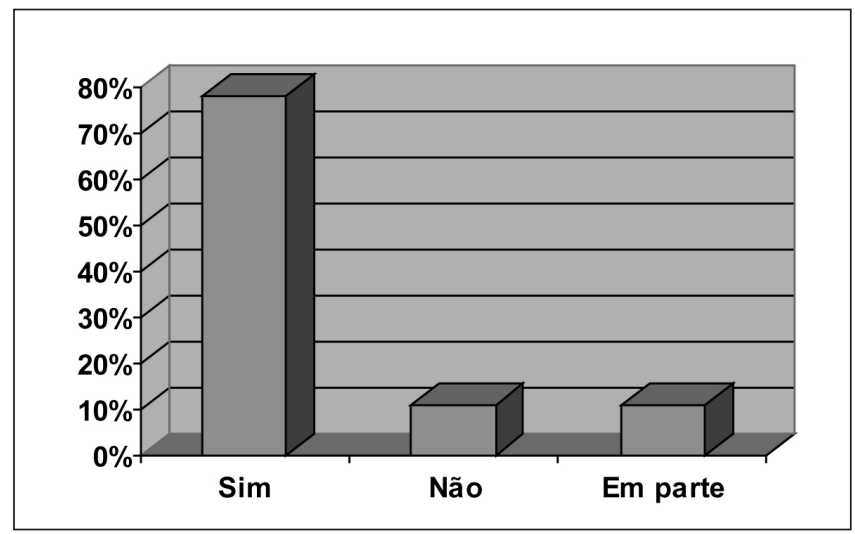

Gráfico 2 - Opinião dos gestores sobre cultura e participação social no Brasil

A expressiva maioria dos gestores $(78 \%)$ respondeu afirmativamente, isto é, os conceitos e as experiências antidemocráticas de avaliação podem influenciar nos níveis de participação social. Eles justificaram suas respostas com os seguintes argumentos:

1) O negativismo pré-concebido pode levar as pessoas a não participarem ou avaliarem de forma negativa.

2) As pessoas têm qualquer processo avaliativo como punitivo. A avaliação deve ter como ênfase a melhoria da instituição.

3) Devido ao descrédito, há uma desmobilização das pessoas quanto à participação social. 
4) Deve-se encarar a avaliação como uma ferramenta para corrigir erros e destacar bons resultados, e não apenas como um processo a ser cumprido.

5) A avaliação não deve ser vinculada à burocratização e à tecnocracia como mecanismos de incentivo à competição e justificativa para cortes e redução de gastos sociais.

6) Há o estereótipo de que a avaliação sempre foi presente apenas para o aluno, portanto, faz-se necessário continuar com a avaliação como um processo fundamental para a instituição.

De acordo com $11 \%$ dos gestores, os conceitos negativos de avaliação podem influenciar, parcialmente, nos níveis de participação, mas a comunidade universitária deve participar ativamente das atividades acadêmicas desenvolvidas pela UFC, tendo vez e voz nas discussões dos melhores caminhos a seguir. Igualmente, $11 \%$ dos gestores não acreditam que esses conceitos possam ter influência sobre a participação social porque a liberdade política e os direitos sociais não permitem prejuízo ou repressão.

Para finalizar, perguntamos o que poderia ser feito para melhorar os níveis de participação dos alunos, professores e técnico-administrativos na AutoAvaliação da UFC. Sugerimos seis opções e deixamos um item em aberto para que pudessem acrescentar comentários (os gestores podiam escolher mais de um fator). O resultado foi o seguinte.

1)A expressiva maioria dos gestores (89\%) asseverou que há que se aprimorar a comunicação interna entre as CPA setoriais e os docentes, os técnico-administrativos e os representantes estudantis (CA's e PET's), através de $e$-mail, reuniões departamentais, de cursos de graduação e de pós-graduação.

2) Segundo $56 \%$ dos gestores, há que se estabelecerem incentivos à participação dos docentes, discentes e técnico-administrativos, através, por exemplo, da inclusão da atividade de membro da CPA na contagem de créditos (horas aula) ou incentivo na ascensão funcional.

3) Para 44\% dos gestores há que se realizar intenso marketing interno no decorrer dos semestres letivos, no âmbito de cada unidade acadêmica da UFC.

Analisando os resultados, a expressiva maioria dos gestores considera que a interação entre a CPA setorial e os diversos segmentos, em nível de graduação e pós-graduação, contribui para melhorar a participação no processo de auto- 
REPRESENTAÇÕES SOCIAIS DOS GESTORES E DOS TÉCNICOS DAS UNIDADES ACADÊMICAS DA UNIVERSIDADE FEDERAL DO CEARÁ (UFC) ACERCA DA AUTOAVALIAÇÃO INSTITUCIONAL

avaliação. Proporção significativa dos gestores acredita que o intenso marketing interno nas unidades acadêmicas pode melhorar a participação.

\subsection{Análise dos questionários dos técnico-administrativos}

Indagamos aos técnico-administrativos se conheciam a proposta de avaliação institucional do Sistema Nacional de Avaliação da Educação Superior (SINAES). As respostas estão configuradas no seguinte gráfico.

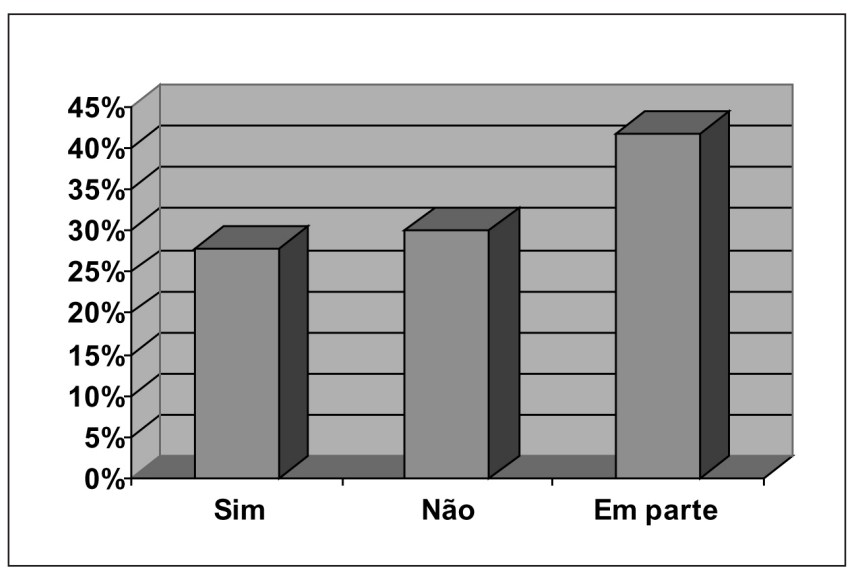

Gráfico 3 - Conhecimento dos técnico-administrativos sobre o SINAES

Proporção significativa dos técnico-administrativos (42\%) asseverou que conhecia parcialmente a sistemática de avaliação do SINAES. Outros $28 \%$ afirmaram conhecer o processo avaliativo, enquanto $30 \%$ revelaram desconhecer a referida sistemática de avaliação. De modo geral, pode-se dizer que $70 \%$ dos técnico-administrativos que participaram da pesquisa conhecem, integralmente ou parcialmente, a sistemática de avaliação contida no SINAES.

Em seguida, perguntamos qual era sua concepção sobre avaliação institucional. Oferecemos cinco fatores explicativos e deixamos um item em aberto para que pudessem acrescentar outros (os técnicos podiam escolher mais de um fator). Expomos abaixo os resultados por ordem de escolha.

1) Para $42 \%$ dos técnicos, a avaliação institucional é uma ferramenta que pode influenciar na melhoria da gestão universitária. 
2) De acordo com 33\% dos técnicos, a avaliação institucional é um instrumento que dispõe de referenciais para priorizar áreas de intervenção, visando à melhoria da qualidade do ensino.

3) Conforme $25 \%$ dos técnicos, a avaliação institucional é um aparato que oferece referenciais para orientar a política educacional do Ministério da Educação.

Sintetizando, expressiva proporção de técnico-administrativos concebe a avaliação institucional como instrumento que oferece referenciais para orientar a política educacional do Ministério da Educação (MEC), para priorizar áreas de intervenção, visando à melhoria da qualidade do ensino e da gestão universitária.

Quanto à participação no processo de Auto-Avaliação Institucional 2005/2006, perguntamos se haviam respondido o questionário eletrônico disponibilizado na página da UFC. Obtivemos o resultado abaixo.

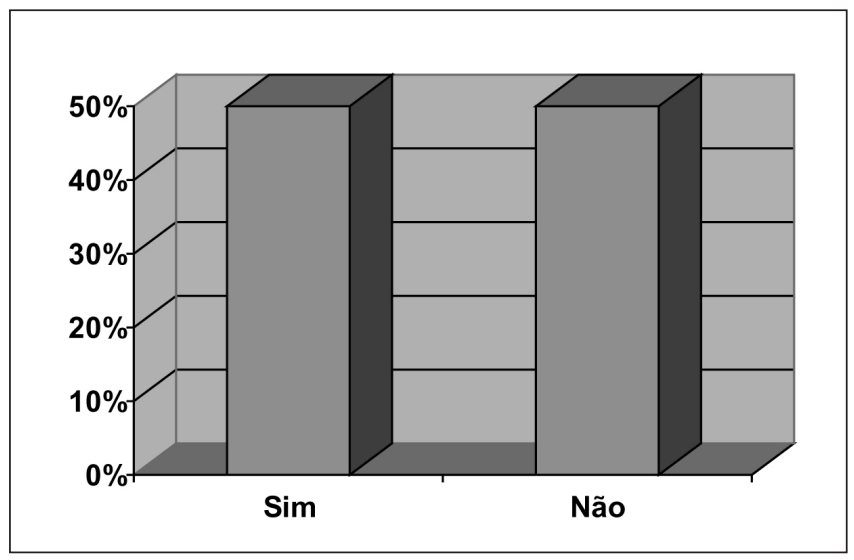

Gráfico 4 - Participação dos técnico-administrativos no processo de Auto-Avaliação Institucional 2005/2006

A análise do gráfico permite verificar que 50\% dos técnico-administrativos que participaram da pesquisa responderam o questionário eletrônico no período da auto-avaliação.

Posteriormente, comentamos com eles os índices de participação dos três segmentos que compõem a UFC no processo de Auto-Avaliação Institucional 2005/2006 por meio dos formulários disponibilizados no site (docentes: 24\%; discentes: $15 \%$, técnico-administrativos: $9 \%$ ). A partir do exposto, indagamos 
quais os fatores que podem estar associados aos baixos índices de participação no processo de Auto-Avaliação Institucional da UFC. Oferecemos quatro opções e deixamos uma em aberto para outras contribuições (os técnicos podiam escolher mais de um fator). Vejamos o resultado.

1. Para a maioria dos técnicos $(55 \%)$, um dos fatores associados à baixa participação dos técnicos na autoavaliação da UFC se deve a ausência de uma cultura de avaliação com visão construtiva e participativa.

2. Para a metade dos técnicos entrevistados, a falta de informação sobre os objetivos e a importância da auto-avaliação é outro dos fatores associados à baixa participação dos técnicos na autoavaliação da UFC.

Para os técnico-administrativos, a falta de participação no processo de auto-avaliação institucional está relacionada à ausência de uma cultura de avaliação com visão construtiva e participativa e na falta de informação sobre os objetivos e a importância da avaliação. Na opção outros dois respondentes acrescentaram as seguintes opiniões: 1) resistência às mudanças: falta trabalhar a cultura antes de implementar qualquer mudança que altere a rotina administrativa e acadêmica da UFC; 2) além da ausência de uma cultura avaliativa, falta de discussão com os técnico-administrativos sobre avaliação institucional.

Refletimos sobre cultura avaliativa no Brasil, onde, mesmo com a abertura política caracterizada pela redemocratização, há certo desgaste em relação à credibilidade dos processos avaliativos. Perguntamos aos técnicos quais os fatores associados a esse suposto descrédito da avaliação. Sugerimos quatro fatores explicativos e deixamos um item em aberto para outras contribuições (os técnicos podiam escolher mais de um fator). Eis o resultado, por ordem de escolha.

1. Para 39\%, um dos fatores responsáveis pelo descrédito dos processos avaliativos é a acentuada verticalização das experiências de avaliação institucional no país.

2. De acordo com $28 \%$, outro fator responsável pelo descrédito dos processos avaliativos está associado ao foco exclusivo nas atribuições de supervisão do MEC.

3. Outros $28 \%$ dos técnicos opinam que estes processos avaliativos são gerencialistas, que praticamente desconsideram as instituições e cursos como sujeitos.

De modo geral, para os técnico-administrativos, o que contribui para a resistência é o fato de as experiências de avaliação no país geralmente serem 
verticalizadas, nas quais o MEC elabora e supervisiona o programa, e as instituições apenas gerenciam os processos.

Por fim, perguntamos o que poderia ser feito para melhorar os níveis de participação dos alunos, professores e técnico-administrativos na Auto-Avaliação da UFC. Oferecemos seis opções e deixamos um item em aberto para acrescentar comentários (os técnicos podiam escolher mais de um fator). Este foi o resultado por ordem de escolha.

1. Para a maioria dos técnicos $(56 \%)$, há que se realizar intenso marketing interno no decorrer dos semestres letivos, no âmbito de cada unidade acadêmica.

2. Conforme metade dos técnicos há que se estabelecerem incentivos à participação dos docentes, discentes e técnicos-administrativos, através da inclusão da atividade de membro da CPA na contagem de créditos (horas aula) ou incentivo na ascensão funcional.

3. De acordo com 39\% dos técnicos, há que se buscar maior comprometimento da Administração Superior da UFC na execução da sistemática de auto-avaliação institucional.

De acordo com os técnico-administrativos, deve-se prosseguir com a sensibilização da comunidade universitária através de marketing interno, bem como estabelecer incentivos para a participação dos diversos atores sociais e buscar maior comprometimento da educação superior.

\section{CONSIDERAÇÕES FINAIS}

Viana (2005) considera que a avaliação educacional às vezes é vista como processo revolucionário que promoverá mudanças imediatas em todo o sistema, abrangendo todos os sujeitos. Nada se faz aos saltos, a avaliação não gera um quadro de revolução. O referido autor leva em conta outro aspecto: as instituições educacionais tendem a ser conservadoras e a avaliação não está comprometida com o conservadorismo. Concordamos com o autor que a avaliação não deve ser vista, nem como um processo revolucionário que resolverá todos os problemas, nem com o descrédito de que nenhuma conseqüência trará, mas como processo que conduz a mudanças desejáveis com as quais está comprometida.

Eis a necessidade de se promover cultura avaliativa capaz de envolver os sujeitos no processo e romper com o conservadorismo. No entanto, devemos 
lembrar que a aculturação de novos hábitos não se dá de forma automática nem imediata: a construção de uma cultura de avaliação é um processo que demanda tempo, continuidade, informação e reflexão, capaz de impulsionar uma consciência institucional e possibilitar uma visão crítica e participativa de avaliação. O papel da instituição é informar sobre o processo avaliativo à comunidade universitária, através dos setores que executam a avaliação. Porém, a conscientização e a participação são processos subjetivos.

A partir da análise das representações dos gestores e de uma amostra de técnico-administrativos das unidades acadêmicas que participaram do ciclo de avaliação 2005/2006, inferimos que os gestores concebem a avaliação institucional como uma ferramenta que visa ao conhecimento das instituições, objetivando a melhoria da gestão universitária, na busca de apoio para sedimentar compromissos, quer financeiro, quer de outra natureza. Para eles, os baixos índices de participação no processo de auto-avaliação estão relacionados, principalmente, à ausência de uma cultura avaliativa com visão construtiva e participativa. Em seguida, esses profissionais citaram fatores como a falta de informação, a despolitização e a falta de compromisso com a instituição. Os gestores sugerem que a interação entre a CPA setorial e os diversos segmentos, em nível de graduação e de pós-graduação, assim como o estabelecimento de incentivos à participação dos docentes, discentes e técnico-administrativos, bem como intenso marketing interno, contribuem conjuntamente para melhorar a participação no processo de auto-avaliação.

Os técnico-administrativos concebem a avaliação institucional como um instrumento que oferece referenciais para orientar a política educacional do Ministério da Educação (MEC), no sentido de priorizar áreas de intervenção, visando à melhoria da qualidade do ensino e da gestão universitária. Para eles, a falta de participação no processo de auto-avaliação institucional está relacionada com a ausência de cultura de avaliação com visão construtiva e participativa, bem como com a falta de informação sobre os objetivos e a importância da avaliação, aliada à resistência às mudanças. Para melhorar a participação da comunidade interna, os técnicos sugerem a sensibilização através do marketing interno, bem como o estabelecimento de incentivos para a participação dos diversos atores sociais.

Como podemos ver, as representações têm um caráter específico, não pelo fato de serem subjetivas, mas pelas próprias condições de produção. De acordo com Bardin (2004), essas condições dizem respeito ao emissor e ao receptor da mensagem, portanto, na análise de conteúdo devemos considerar as condições de produção (emissor) e reprodução (receptor). Para Jodelet (2001) o lugar, a 
posição social ou as funções que os indivíduos ocupam determinam os conteúdos representacionais e sua organização.

Analisando as representações de gestores e técnico-administrativos percebemos essas especificidades em relação à inserção social e aos interesses inerentes a cada segmento. Nesse sentido, Bourdieu (2007) Falta referenciar considera que todo campo é lugar de uma luta mais ou menos declarada pela definição da força simbólica das partes envolvidas e nunca é completamente independente de sua posição no jogo. O espaço social é multidimensional, conjunto aberto de campos relativamente autônomos, quer dizer, subordinados quanto ao seu funcionamento e suas transformações, de modo mais ou menos direto ao campo de produção econômica. No interior de cada um dos subespaços ocorrem lutas de diferentes formas (sem por isso se constituírem necessariamente em grupos antagônicos) por meio da constituição de grupos organizados com o objetivo de assegurarem a defesa dos interesses de seus membros. Ou seja, o autor situa e define o campo social, aparentemente unificado, que compõe a instituição com as suas segmentações e relações de poder.

Acreditando que cultura é representação e não obediência a regras, o que se poderia dizer que foi a idéia originária desse estudo, foi a pretensão de buscar compreender um pouco desse emaranhado de relações que dão vida ao cotidiano da UFC através dos diversos sujeitos que ali estudam, pesquisam, trabalham, constroem, sonham, que nos motivou a fazê-lo. Almejamos contribuir com a discussão sobre avaliação e o desenvolvimento de uma cultura institucional avaliativa e participativa na UFC.

Durante o desenvolvimento da pesquisa de campo, tivemos a oportunidade de conhecer in loco as nove unidades acadêmicas da sede da UFC. Compreendemos que a UFC é um complexo cultural na própria especificidade de cada área (centro, faculdade, curso) com seus interesses e objetivos, bem como na diversidade cultural dos diversos segmentos que a compõe. Porém, no íntimo de cada diferença (cultural, política, econômica, tecnológica, ideológica), encontramos um ponto em comum, um álibi para encorajar e amenizar o que o coletivo no seu individualismo nos provoca: o desejo de contribuir para o aprimoramento e o desenvolvimento da UFC suscita uma solidariedade orgânica, um elo cultural. 
REPRESENTACCÕES SOCIAIS DOS GESTORES E DOS TÉCNICOS DAS UNIDADES ACADÊMICAS DA UNIVERSIDADE FEDERAL DO CEARÁ (UFC) ACERCA DA AUTOAVALIAÇÃO INSTITUCIONAL

\section{REFERÊNCIAS}

ANDRIOLA, W. B. (Org.). Avaliação: múltiplos olhares em torno da educação. Fortaleza: UFC, 2005.

ANDRIOLA, W. B. Propostas estatais voltadas à avaliação do Ensino Superior brasileiro: breve retrospectiva histórica do período 1983-2008. Revista Electrónica Iberoamericana Sobre Calidad, Eficacia y Cambio en Educación, Chile, v. 6, p. 127-148, 2008.

BARDIN, L. Análise de conteúdo. 3. ed. Lisboa: Edições 70, 2004.

BELLONI, I. Avaliação institucional: um instrumento de democratização da educação. Linhas Críticas, Brasília, v. 5, n. 9, p. 7-30, 1999.

BOURDIEU, P. O poder simbólico. 11. ed. Rio de Janeiro: Bertrand Brasil, 2007.

BRASIL. SINAES - Sistema Nacional de Avaliação da Educação

Superior: da concepção à regulamentação. 4. ed. Brasília: INEP, 2007.

BRASIL. Ministério da Educação. Censo da Educação Superior 2007: resumo técnico, Brasília: INEP, 2009.

CHAUÍ, M. Brasil. Mito fundador e sociedade autoritária. São Paulo: Perseu Abramo, 2000.

DEMO, P. Prefácio. In: GADOTTI, M. Avaliação qualitativa: polêmicas do nosso tempo. 6. ed. Campinas: Autores Associados, 1999.

DIAS SOBRINHO, J. Sobre a proposta do Sistema Nacional de Avaliação da Educação Superior. Avaliação, Campinas, v. 9, n. 1, p. 113-24, 2004

DIAS SOBRINHO, J.; RISTOFF, D. (Org.). Avaliação e compromisso público. A educação superior em debate. Florianópolis: Insular, 2003.

FERNANDES, M. E. A. Avaliação institucional da escola: base teórica e construção do projeto. Fortaleza: Ed. UECE, 2001.

JODELET, D. As representações sociais. Trad. Lilian Ulup, Rio de Janeiro: Ed. UERJ, 2001 
MORGAN, G. Imagens da organização. Trad. Cecília Whitaker Bergamini, Roberto Coda. São Paulo: Atlas, 1996.

SPINK, M. J. P. O conceito de representação social na abordagem psicossocial. Cadernos de Saúde Pública, Rio de Janeiro, v. 9, n. 3, p. 3008, 1993.

SUANNO, M. V. R. Princípios para instrumentalização do processo de autoavaliação institucional. Uniciência, Anápolis, n. 9, p. 81-91, 2002.

UFC. COMISSÃO PRÓPRIA DE AVALIAÇÃO. Auto-Avaliação Institucional da Universidade Federal do Ceará (2005-2006): relatório final. Fortaleza: UFC, 2006.

VIANNA, H. M. Avaliação de programas educacionais: duas questões. Estudos em Avaliação Educacional, São Paulo, v. 16, n. 32, p. 43-55, jul./ dez., 2005.

ZÁKIA, S. Avaliação institucional no âmbito das escolas de ensino fundamental e médio. Fortaleza, 2008. Palestra apresentada no IV Congresso Internacional em Avaliação Educacional/UFC, 2008. 
Este artigo sofreu alterações por solicitação do editor em Nov/2010 conforme ERRATA

publicada no Volume 15 Número 3 do periódico. (http://www.scielo.br/pdf/aval/v15n3/12.pdf) 